Oral Abstracts

Aim: To develop an algorithm for automated analysis of the EEG background activity of the continuous EEG from day one to three.

Method: 42 healthy infants with $\mathrm{GA}<31$ wk were included, monitored (NicoletOne monitor) continuously for 3 days soon after birth. 8 EEG electrodes were applied. The data were analyzed by visually removing artifacts (pruned), and by an algorithm removing the highest $5,10,15$ or $20 \%$ of the total absolute bandpower (tABP).

Results are depicted in fig 1. (ס-tABP)

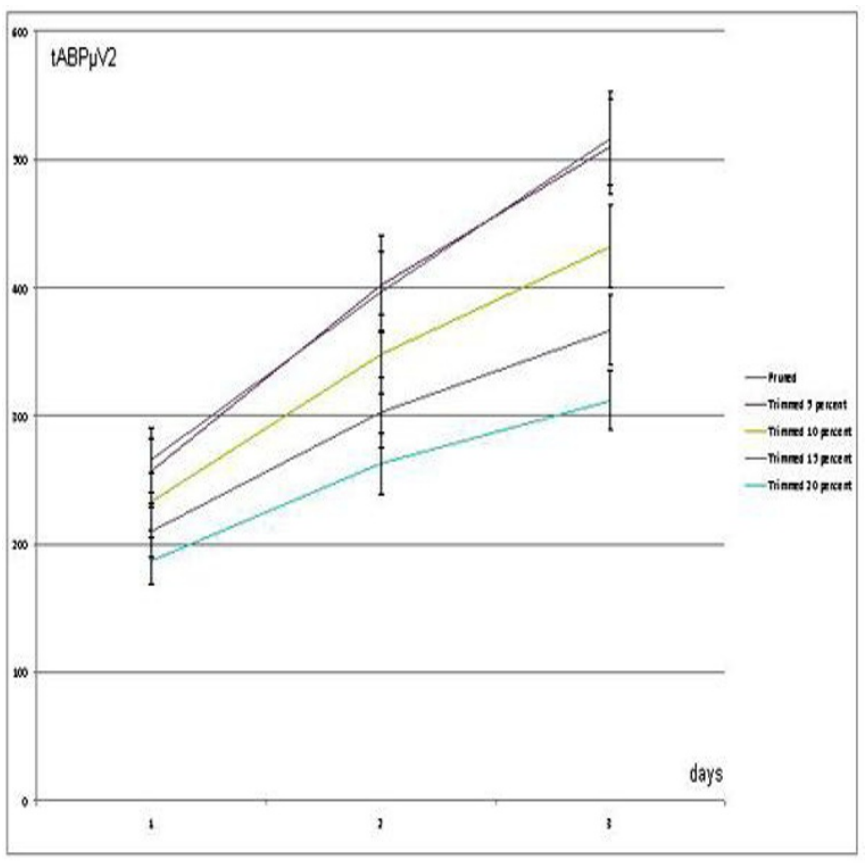

[fig.1]

There were good correlations between the pruned and the 4 different algorithms used, the $5 \%$ removal showing the closest relationship with $95 \%$ match of the removed data.

Conclusion: This study shows a good relationship between pruned and automated analyses of the EEG recording.

\section{EFFECT OF CARBON DIOXIDE ON BACKGROUND CEREBRAL ELECTRICAL ACTIVITY IN PRETERM INFANTS DURING THE FIRST 4 WEEKS AFTER BIRTH}
A. Raina1, M. Sarwar ${ }^{1}$, A. Hendrickson ${ }^{1}$, S. Victor ${ }^{2}$
${ }^{1}$ Newborn Intensive Care Unit, Central Manchester Foundation Trust, ${ }^{2}$ Developmental and Regenerative Biomedicine Research Group, University of Manchester, Manchester, UK

Background: Hypocarbia causes slowing of background cerebral electrical activity while hypercarbia causes prolonged interburst intervals in very low birth weight babies during the first three days after birth ${ }^{1}$.

\begin{abstract}
Aim: This study aims to determine whether changes in blood gases were associated with changes in background cerebral electrical activity in preterm infants during the first four weeks after birth.
\end{abstract}

Methods: An observational study is being conducted at the Newborn Intensive Care Unit, St Mary's Hospital, Manchester. 75 minute electroencephalography (EEG) recordings were performed every week for 4 weeks in babies born before 32 weeks gestational age. Capillary blood gases were measured midway during each EEG recording. EEG was analysed by manual calculation of interburst interval. $\mathrm{pH}, \mathrm{pCO} 2$, base deficit and bicarbonate were entered as variables in a stepwise linear regression model.

Results: 39 EEG recordings have been performed on 13 babies. The corrected gestational age at the time of EEG recording ranged from 24 - 34 weeks. The median (range) of blood gas measurements were: $\mathrm{pH}: 7.3$ (7.18 - 7.43); partial pressure of carbon dioxide (pCO2): $6.68 \mathrm{kPa}$ (5.06 - 10.2); Base deficit: 1.5 (8.9 to -10.7); Bicarbonate: $22.15 \mathrm{mmol} / \mathrm{L}$ (16.7 - 33.1). Corrected gestational age was related to duration of interburst interval $(r=0.699 ; p<0.001)$. In a linear regression model, corrected gestational age and $\mathrm{pCO} 2$ was related to duration of interburst interval $(r=0.769 ; p<0.001)$.

Conclusion: There is suppression of EEG at higher levels of $\mathrm{pCO} 2$.

References: (1) Victor S et al. Pediatr Res 2005 Sep;58(3):579-85. 